\title{
The Concept of the Pre-lecture
}

\section{Summary}

This article reviews previously published work demonstrating how pre-lecture support for students can help improve end of year examination performance.

Subject area: Physical Sciences

\section{Description}

At the start of each lecture course, one lecture was replaced by a pre-lecture. In this, a quick check of background knowledge allowed students to classify themselves as needing help or able to offer help. Students then worked in pairs on material designed to revise the background material necessary to make sense of the lecture course.

End of year examination performance showed that student performance was no longer related to entry qualifications in chemistry: the least well qualified did as well as the better qualified.

This was observed for two successive years but, for the next three years pre-lectures were not offered. Student performance fell despite the increased lecture time and the least well qualified did significantly worse than the better qualified.

In the sixth year, new teaching materials were introduced, designed to mimic the prelecture concept. Again, the least well qualified did as well as the better qualified.

\section{Type of activity}

A set of Teaching Materials (called Chemorganisers) available at: http://www.gla.ac.uk/centres/scienceeducation/Chemorg/ChemorganisersHomePage.html Project covered the years 1993-1999

\section{Application}

Numerous aspects of chemistry, set at introductory level but the idea applies to any discipline. Students can be referred to the materials.

Pre-lectures are easy to set up in any discipline, and have been shown to be highly effective.

\section{Author(s)}

The work was conducted by two PhD students: Dr Craig Gray (deceased) and Dr Ghassan Sirhan

\section{Contact details}

Dr Norman Reid, Centre for Science Education, St Andrews Building, University of Glasgow, Glasgow, G3 6NH

N.Reid@mis.gla.ac.uk 
New Directions in the Teaching of Physical Sciences

\section{References}

1. Ghassan Sirhan, Craig Gray, Alex H Johnstone and Norman Reid, Preparing the Mind of the Learner, University Chemistry Education, 3(2), 1999, 43-46.

2. Ghassan Sirhan and Norman Reid, Preparing the Mind of the Learner - Part 2, University Chemistry Education, 5, 2001, 52-58

3. G. Sirhan \& N. Reid, An Approach in Supporting University Chemistry Teaching, Chemistry Education Research and Practice, 2002, Vol. 3, No. 1, pp. 65-75 (http://www.uoi.gr/cerp/) 